\title{
Exploring the heterogeneity of effects of corticosteroids on acute respiratory distress syndrome: a systematic review and meta-analysis
}

\author{
Sheng-Yuan Ruan ${ }^{1,2}$, Hsien-Ho Lin ${ }^{1 *}$, Chun-Ta Huang ${ }^{2}$, Ping-Hung Kuo ${ }^{2}$, Huey-Dong Wu ${ }^{2}$ and Chong-Jen Yu ${ }^{2}$
}

\begin{abstract}
Introduction: The effectiveness of corticosteroid therapy on the mortality of acute respiratory distress syndrome (ARDS) remains under debate. We aimed to explore the grounds for the inconsistent results in previous studies and update the evidence.

Methods: We searched MEDLINE, Cochrane Central Register of Controlled Trials and Web of Science up to December 2013. Eligible studies included randomized clinical trials (RCTs) and cohort studies that reported mortality and that had corticosteroid nonusers for comparison. The effect of corticosteroids on ARDS mortality was assessed by relative risk (RR) and risk difference (RD) for ICU, hospital, and 60-day mortality using a random-effects model.

Results: Eight RCTs and 10 cohort studies were included for analysis. In RCTs, corticosteroids had a possible but statistically insignificant effect on ICU mortality $(R D,-0.28$; $95 \%$ confidence interval $(C l),-0.53$ to -0.03 and $R R, 0.55$; $95 \% \mathrm{Cl}, 0.24$ to 1.25 ) but no effect on 60 -day mortality (RD, $-0.01 ; 95 \% \mathrm{Cl},-0.12$ to 0.10 and $\mathrm{RR}, 0.97 ; 95 \% \mathrm{Cl}, 0.75$ to 1.26). In cohort studies, corticosteroids had no effect on ICU mortality (RR, 1.05; $95 \% \mathrm{Cl}, 0.74$ to 1.49) but non-significantly increased 60-day mortality (RR, 1.30; 95\% Cl, 0.96 to 1.78). In the subgroup analysis by ARDS etiology, corticosteroids significantly increased mortality in influenza-related ARDS (three cohort studies, RR, 2.45, 95\% Cl, 1.40 to 4.27).

Conclusions: The effects of corticosteroids on the mortality of ARDS differed by duration of outcome measures and etiologies. Corticosteroids did not improve longer-term outcomes and may cause harm in certain subgroups. Current data do not support routine use of corticosteroids in ARDS. More clinical trials are needed to specify the favorable and unfavorable subgroups for corticosteroid therapy.
\end{abstract}

\section{Introduction}

Despite advances in critical care medicine over the past decades, the mortality rate for acute respiratory distress syndrome (ARDS) remains high [1-3]. Because dysregulated inflammation is the cardinal feature of ARDS [2,4], systemic corticosteroids have been considered a potentially beneficial therapy. However, previous randomized trials have failed to provide convincing evidence to prove the efficacy of corticosteroids in decreasing the mortality of ARDS [5-8]. Only secondary outcomes, such as oxygenation improvement and reduction of the duration of mechanical ventilation, have shown consistent findings in favor of corticosteroid therapy.

\footnotetext{
* Correspondence: hsienho@gmail.com

${ }^{1}$ Graduate Institute of Epidemiology and Preventive Medicine, National

Taiwan University, No.17 Xu-Zhou Road, Taipei 10020, Taiwan

Full list of author information is available at the end of the article
}

Published meta-analyses about corticosteroid therapy for ARDS reported inconsistent conclusions [9-13]. Different study selections and heterogeneity on mortality endpoints and etiologies of ARDS may account for the inconsistent study results in previous meta-analyses. Measuring the treatment effects at short-term or longerterm follow-up may influence study results, because therapeutic effects of corticosteroids develop early but some adverse effects, such as infection, develop late. Using short-term outcome as the study endpoint may underestimate the risk of corticosteroid therapy and overestimate the overall benefit. In addition, the mechanisms of lung injury and fibroproliferative response to injury vary in pulmonary and extrapulmonary ARDS [14]. Therefore, the treatment response to corticosteroids in ARDS may be different in ARDS of different etiologies. However, the influence of the etiologies of ARDS on 
outcomes of corticosteroid therapy has not been evaluated in previous studies.

We conducted a systematic review and meta-analysis of corticosteroid therapy in ARDS with the aim of updating the best available evidence and exploring the source of observed heterogeneity.

\section{Materials and Methods}

\section{Search strategy}

This systematic review was conducted using an a priori published protocol submitted to the PROSPERO website (Registration No.: CRD42012002583) and reported according to the Preferred Reporting Items for Systematic Reviews and Meta-Analyses (PRISMA) criteria [15]. No institutional review board (IRB) approval or consents were needed for this systematic review because it evaluated published studies. We searched MEDLINE via the NCBI Entrez system, Cochrane Central Register of Controlled Trials (CENTRAL) and Web of Science (WOS) up to December 2013. We also screened the bibliographies of retrieved studies and recent review articles to identify additional trials.

Keyword search was performed in MEDLINE, CENTRAL and WOS using the following terms: 'corticosteroids' AND ('ALI' OR 'acute lung injury' OR 'ARDS' OR 'acute respiratory distress syndrome'). The search was then limited to human studies. We also used MeSH term search in MEDLINE with the following terms: ('respiratory distress syndrome, adult' OR 'acute lung injury') AND ('hydroxycorticosteroids' OR 'glucocorticoids'). No language restrictions were applied.

The inclusion criteria included randomized controlled trial (RCT) and cohort study designs that reported mortality outcomes and had corticosteroid nonusers for comparison.

\section{Quality assessment and data extraction}

Two investigators (SYR and CTH) independently extracted data from the included studies into standardized data recording forms. Quality assessment of these studies was done using the Cochrane Risk of Bias Tool for RCTs and the Newcastle-Ottawa Quality Assessment Scale for cohort studies $[16,17]$.

\section{Outcome measurement}

The primary study endpoint was all-cause mortality. Different mortality measures were reported in the studies, including ICU mortality, hospital mortality and 60-day mortality. According to the duration of mean ICU and hospital stay reported in the included studies $[7,8,18]$, we classified ICU mortality as short-term outcome, hospital mortality as a mid-term outcome, and 60-day mortality as a longer-term outcome. Additionally, two studies reported 14-day and 45-day mortality [5,19], and these two outcome measures were classified as ICU mortality and 60-day mortality, respectively. The secondary study endpoint was nosocomial infections related to corticosteroid therapy.

\section{Statistical analysis}

Relative risk (RR) and risk difference (RD) were used as measurements of association. Outcome measures were pooled using a random-effects model because of anticipated heterogeneity among included studies. We treated risk ratio and hazard ratio as $\mathrm{RR}$ when pooling across studies. We estimated the point estimate and 95\% confidence interval $(95 \% \mathrm{CI})$ of the summary effect estimate (RR or RD). RCTs and cohort studies were analyzed separately. When one arm of a study contained no events, 0.5 was added to all cells of the two-by-two table. Heterogeneity was explored using the $Q$ statistic and $\mathrm{I}^{2}$. Heterogeneity was considered low, moderate, and high by $\mathrm{I}^{2}$ values of $25 \%, 50 \%$, and $75 \%$, respectively [20]. We hypothesized that the treatment response to corticosteroids in ARDS patients may vary by different mortality endpoints, by different etiologies of ARDS, and by different timing for starting treatment. We, therefore, conducted subgroup analyses to explore whether the treatment response varied by these variables of interest. All tests were two-sided and $P$ values of $<0.05$ were deemed significant. The data were analyzed using Stata software, V.11 (StataCorp).

\section{Results}

We identified 1,771 citations from the search of electronic databases. Using the predefined inclusion and exclusion criteria (Figure 1), seven RCTs [5-8,19,21,22], one post-hoc analysis of RCT [23], and 10 cohort studies were included for evaluation [18,24-32]. The post-hoc analysis was classified as RCT for the analysis. Of the eight RCTs, three trials studied preventive rather than therapeutic use of corticosteroids in ARDS. A total of 1,474 subjects were analyzed, including 725 from RCTs and 749 from cohort studies. The details of the included studies are summarized in Additional file 1: e-Table S1. Quality assessment of the included studies suggested a low risk of bias in most RCTs (Additional file 1: e-Table S2) but the comparability and representativeness of the study patients were concerns in cohort studies (Additional file 1: e-Table S3, e-Table S4).

\section{Mortality outcomes}

Figure 2 shows the effects of corticosteroid therapy on mortality. Pooled results from all RCTs suggested that corticosteroids had no significant effect on mortality (RR, 0.91; 95\% C.I., 0.71 to 1.18). Visual inspection of the forest plot and the estimated $\mathrm{I}^{2}(57 \%)$ revealed moderate heterogeneity among the included studies. To explore the influence of different mortality endpoints, we conducted 


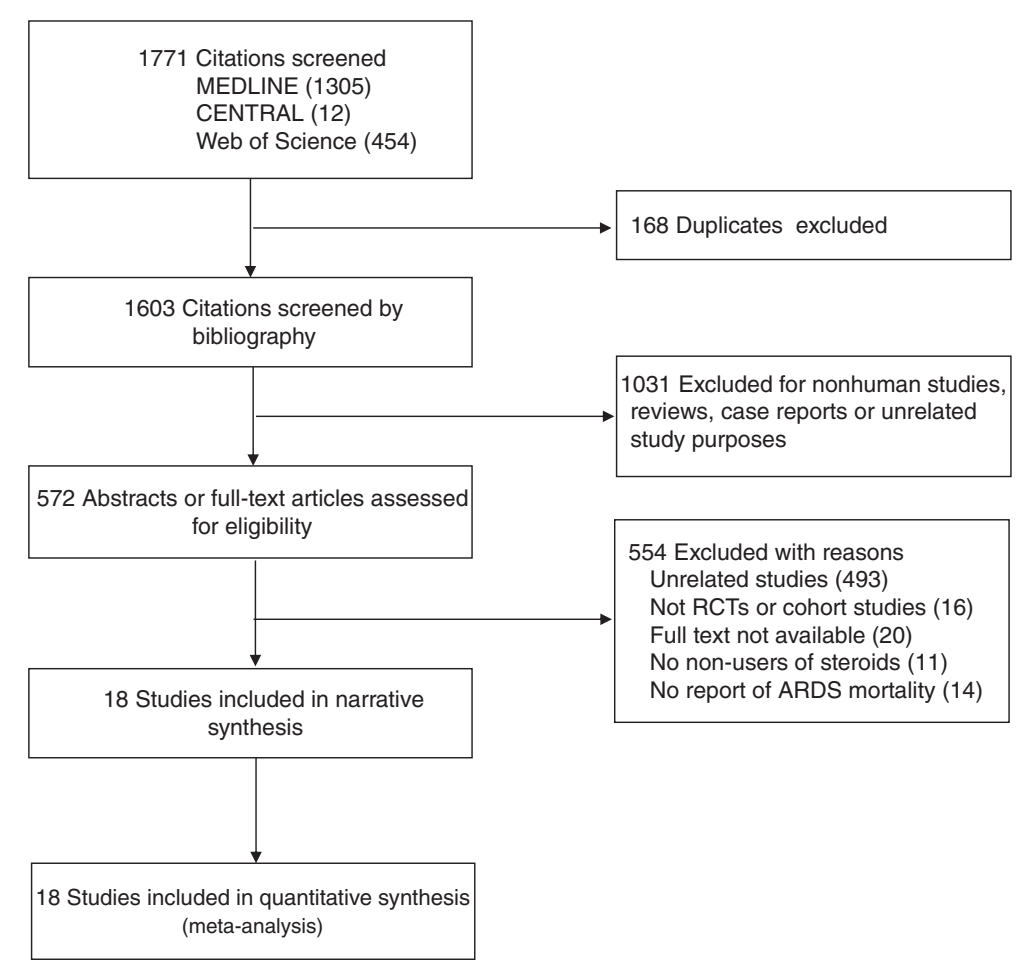

Figure 1 Number of studies evaluated at each stage of the systematic review.

subgroup analysis by different mortality endpoints (Table 1). The results suggested that corticosteroids had a possible but statistically insignificant effect on short-term (ICU) mortality (RR, 0.55 ; $95 \%$ CI, 0.24 to 1.25 and RD, -0.28 ; $95 \% \mathrm{CI},-0.53$ to -0.03 ) but did not decrease 60 -day mortality. Within-study observations in those studies reporting two mortality outcomes by different follow-up durations also suggested similar findings, that the disadvantage of corticosteroid therapy increased by prolonging the follow-up period (Additional file 1: e-Table S5). In cohort studies, corticosteroids had no effect on ICU mortality but there was a trend of increased mortality on 60-day mortality (Table 1). A funnel plot of standard error versus risk ratio for mortality did not suggest significant publication bias (Additional file 2: e-Figure S1, e-Figure S2).

\section{Etiologies of ARDS}

We also conducted a subgroup analysis by different etiologies of ARDS. For this analysis, we classified the study population into four groups: unselected ARDS, sepsisrelated ARDS (infection-related ARDS $>70 \%$ of cases), influenza-related ARDS, and post-operative ARDS. Table 2 summarizes the treatment outcome of corticosteroids in these four groups of ARDS patients. The responses to corticosteroid therapy differed among different etiologies of ARDS. Notably, corticosteroids significantly increased mortality in influenza-related ARDS (RR, 2.44;
95\% CI, 1.4 to 4.27). One cohort study reported good treatment outcome in patients with post-operative ARDS but the sample size was very small [29].

\section{Infection risk of corticosteroids}

The definitions and observational durations of infectious complications varied greatly among included studies (Additional file 1: e-Table S6). The observed durations of infectious complications ranged from 7 days to 28 days. Pooled data showed conflicting findings that corticosteroids tend to increase infection risk in cohort studies (risk ratio, 1.35, 95\% CI, 0.99 to 1.84 ) but decrease infection risk in RCTs (risk ratio, $0.83,95 \% \mathrm{CI}, 0.65$ to 1.06 ) (Figure 3).

\section{Discussion}

Our study found that the mortality outcomes of corticosteroid therapy in ARDS differed by duration of outcome measures. Corticosteroids had a possible but statistically insignificant effect on short-term mortality in RCTs but did not decrease longer-term mortality in either RCTs or cohort studies (Table 1). Within-study observation in studies reporting two mortality endpoints also suggested that the benefit of corticosteroid therapy decreased when follow-up was prolonged $[7,8,23]$. This raises a concern that corticosteroid therapy in ARDS may bring initial benefits by suppressing the inflammatory process and reducing alveolocapillary permeability $[4,33,34]$, but the 


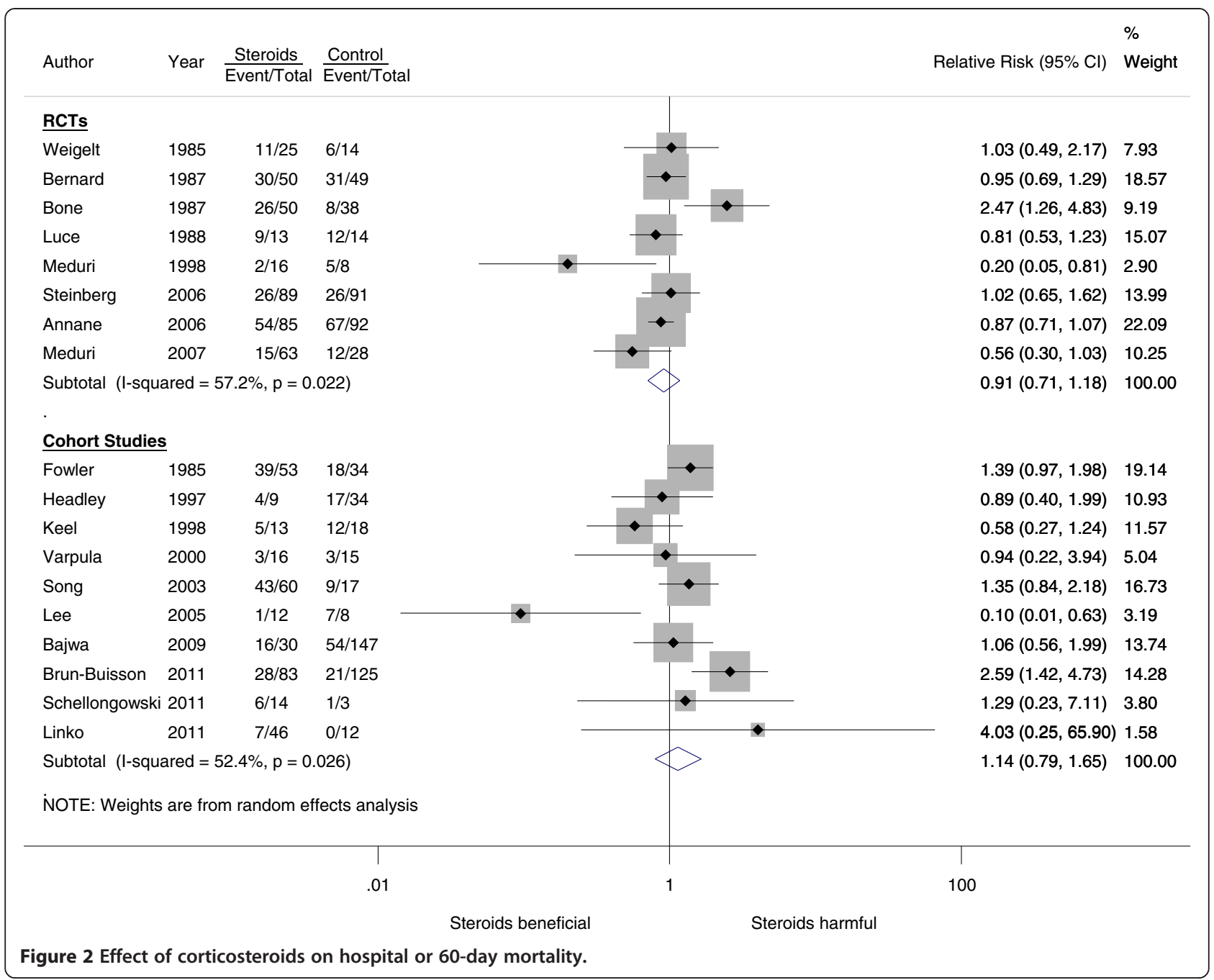

beneficial effects are soon counteracted by the delayed onset of adverse effects, such as immunosuppression and altered tissue repair $[35,36]$. We also found that the effect of corticosteroid therapy differed among different populations of ARDS patients. Corticosteroids may cause harm in certain ARDS subgroups, such as influenzarelated ARDS. Taken together, current data do not support routine use of corticosteroids in ARDS. Given the heterogeneous nature of ARDS and the pleiotropic effects of corticosteroids, more clinical trials are needed to specify

Table 1 Short-term and longer-term effects of corticosteroids on mortality

\begin{tabular}{|c|c|c|c|c|c|c|}
\hline \multirow[t]{2}{*}{ Mortality endpoints } & \multicolumn{2}{|c|}{ Number of } & \multicolumn{2}{|c|}{ Relative risk } & \multicolumn{2}{|c|}{ Risk difference } \\
\hline & Studies & Patients & Effect size $(95 \% \mathrm{Cl})$ & $1^{2}$ & Effect size $(95 \% \mathrm{Cl})$ & $1^{2}$ \\
\hline \multicolumn{7}{|c|}{ Randomized controlled trials ${ }^{a}$} \\
\hline ICU mortality & 3 & 292 & 0.55 (0.24 to 1.25$)$ & $75 \%$ & $-0.28(-0.53 \text { to }-0.03)^{*}$ & $76 \%$ \\
\hline Hospital mortality & 2 & 201 & 0.49 (0.12 to 2.07$)$ & $77 \%$ & $-0.26(-0.65$ to 0.13$)$ & $75 \%$ \\
\hline 60-day mortality & 2 & 279 & 0.97 (0.75 to 1.26$)$ & $0 \%$ & $-0.01(-0.12$ to 0.10$)$ & $0 \%$ \\
\hline \multicolumn{7}{|l|}{ Cohort studies } \\
\hline ICU mortality & 5 & 226 & $1.05(0.74$ to 1.49$)$ & $1 \%$ & Not calculable & - \\
\hline Hospital mortality & 4 & 317 & $1.00(0.23$ to 4.34$)$ & $75 \%$ & Not calculable & - \\
\hline 60-day mortality & 2 & 264 & $1.30(0.96$ to 1.78$)$ & $0 \%$ & Not calculable & - \\
\hline
\end{tabular}

${ }^{a}$ Trials testing preventive therapy of corticosteroids for acute respiratory distress syndrome (ARDS) were excluded. Some studies provided data on both short-term and longer-term mortality. For cohort studies, only pooled relative risk was provided because adjusted results were needed for data pooling $* P$-value $<0.05$. 
Table 2 Effects of corticosteroids on mortality in different etiologies of ARDS

\begin{tabular}{|c|c|c|c|c|}
\hline Etiology of ARDS ${ }^{a}$ & Number of studies & Number of patients & Relative risk $(95 \% \mathrm{Cl})$ & $1^{2}$ \\
\hline \multicolumn{5}{|l|}{ Unselected ARDS } \\
\hline Randomized controlled trials & 3 & 370 & 0.88 (0.65 to 1.18$)$ & $28 \%$ \\
\hline Cohort studies & 4 & 238 & 1.12 (0.78 to 1.60$)$ & $40 \%$ \\
\hline \multicolumn{5}{|l|}{ Influenza-related ARDS ${ }^{b}$} \\
\hline Cohort studies & 3 & 283 & $2.45(1.40$ to 4.27$) * *$ & $0 \%$ \\
\hline \multicolumn{5}{|l|}{ Sepsis-related ARDS } \\
\hline Randomized controlled trials & 2 & 201 & 0.50 (0.12 to 2.02$)$ & $76 \%$ \\
\hline Cohort studies & 2 & 208 & $1.04(0.58$ to 1.85$)$ & $0 \%$ \\
\hline \multicolumn{5}{|l|}{ Post-operative ARDS ${ }^{b}$} \\
\hline Cohort studies & 1 & 20 & $0.10(0.01$ to 0.63$) *$ & - \\
\hline
\end{tabular}

${ }^{a}$ Excludes the studies of preventive use of corticosteroids; ${ }^{b}$ no randomized controlled trials available. ${ }^{*} P$-value $<0.05$. ${ }^{*} P$-value $<0.005$. ARDS, acute respiratory distress syndrome.

the favorable and unfavorable subgroups for corticosteroid therapy. For more comprehensive assessment of the effects of corticosteroid therapy, future studies should evaluate a mortality endpoint of adequate duration and the 60-day mortality used by the ARDSnet appears to be a reasonable study endpoint [6].
Our study demonstrated the diverse treatment effects of corticosteroids among different etiologies of ARDS (Table 2). It is biologically plausible that different etiologies of ARDS have different responses to corticosteroid therapy because the pulmonary fibroproliferative response to injury may occur in an injury-specific rather than a

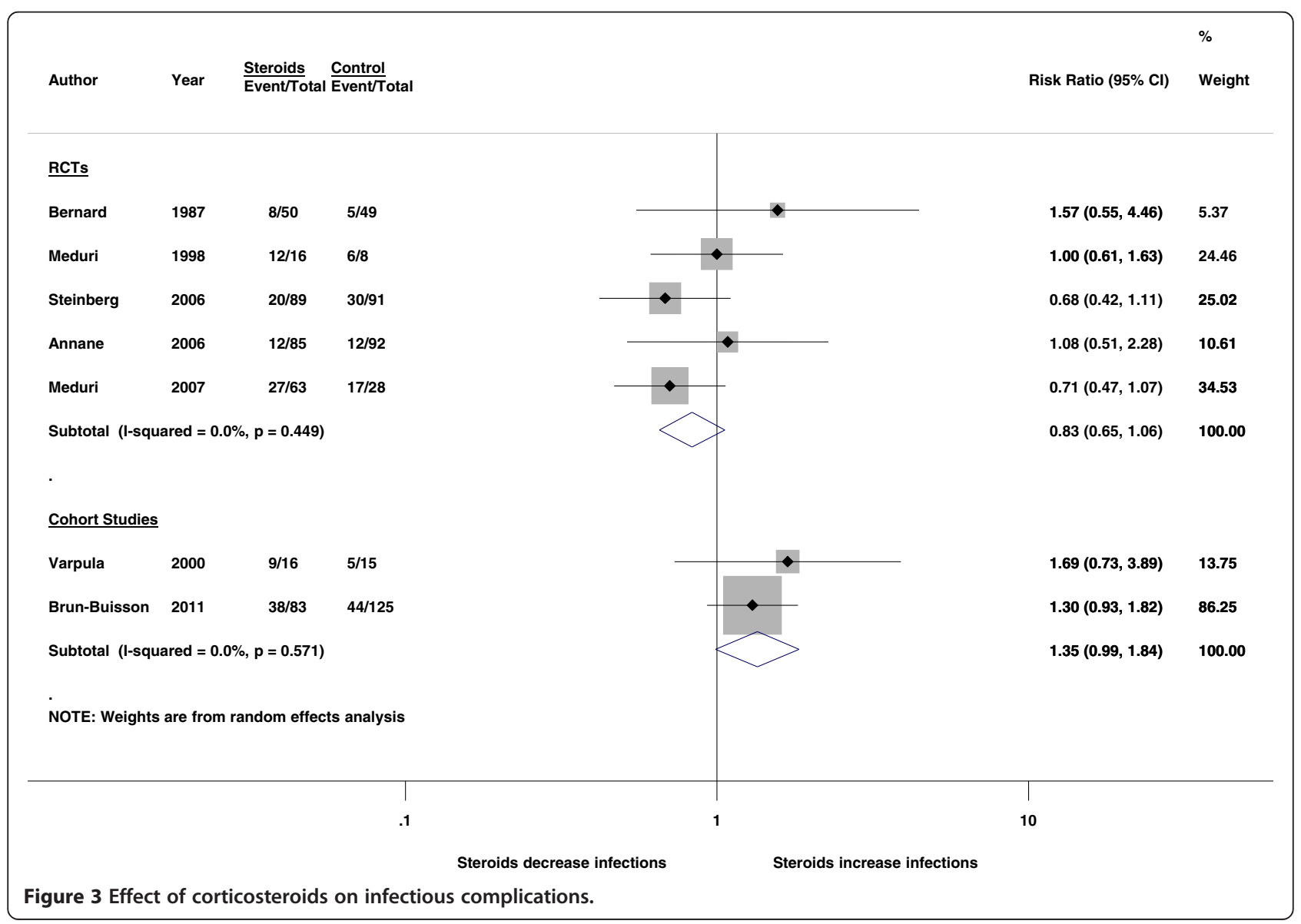


stereotyped manner [14]. The main damage targets differ in ARDS caused by different etiologies $[37,38]$. Therefore, it is not surprising that the efficacy of corticosteroid therapy differs among different etiologies. Additionally, our analysis showed that corticosteroids significantly increased mortality in influenza-related ARDS. The poorer outcome may be attributed to prolonged viral shedding and an increased risk of superinfection [39,40]. An expert review also advised against use of corticosteroids in the management of H1N1 influenza A infection [41].

The dosage and timing of corticosteroid therapy in ARDS has changed over the last decades. Based on the equivalent doses of methylprednisolone, studies before 1990 usually used a high daily dose $(30 \mathrm{mg} / \mathrm{kg})$ and short period ( $\leq 2$ days) regimen to prevent or treat ARDS. In the following two decades, most studies used a protocol of daily dose of $\leq 2 \mathrm{mg} / \mathrm{kg}$ with a gradual taper. Some investigators suggested different treatment dosages for early ARDS and persistent ARDS in which a duration of ARDS $\leq 3$ days was considered as early ARDS and $\geq 5$ days as persistent or unresolving ARDS [4]. The treatment dose was suggested to be $\leq 1 \mathrm{mg} / \mathrm{Kg}$ for early ARDS $[7,23]$, and $2 \mathrm{mg} / \mathrm{Kg}$ for persistent ARDS [6,8]. We summarized the treatment outcomes of corticosteroid therapy initiated at different stages of ARDS (Table 3). Our analysis found that patients with persistent ARDS seemed more likely to benefit from corticosteroid therapy. In addition, the subgroup analysis of the ARDSnet steroid study suggested against starting corticosteroid therapy $>14$ days after the onset of ARDS [6]. These findings suggest a subgroup of ARDS might benefit most from corticosteroid therapy: persistent ARDS with the onset of ARDS $<14$ days. Persistent ARDS indicates a specific subgroup or phenotype of ARDS that is characterized by exaggerated or unresolving lung inflammation [4]. In this subgroup, the benefit of corticosteroid therapy may outweigh the treatment risk. Dosage and administration schedules may also affect treatment outcomes of corticosteroids. However, it was difficult to evaluate the effects of these two factors in the study-level analysis. Cohort studies did not use standardized treatment protocols and individual- level data are needed to conduct such analyses. In RCTs, therapeutic trials usually used a low-dose regimen ( 1 to $2 \mathrm{mg} / \mathrm{kg} /$ day) and similar administration schedules.

Published meta-analyses reached inconsistent conclusions on the role of corticosteroids for ARDS [9-13]. We summarize the study conclusions and study selection strategy of previous meta-analyses in Table 4. Among the included studies in these meta-analyses, an extremely protective effect for corticosteroids was observed in the two studies published by Meduri $[7,8]$, but the effects were neutral and modest in other trials. In addition, inclusion or exclusion of trials of using corticosteroids in severe pneumonia into analysis also had an impact on the results of meta-analysis. Confalonieri and Meduri reported remarkable mortality reduction by corticosteroid therapy in a severe pneumonia study [42]. Previous meta-analyses reporting significant mortality reduction of corticosteroid therapy usually included this pneumonia study $[12,13]$. However, a large cohort study using a registry database reported that low-dose corticosteroids were associated with an increased mortality in pneumonia with septic shock [43].

Systemic corticosteroid therapy may bring several unfavorable side effects [36,44], and one major concern in patients with ARDS is an increased risk of nosocomial infection secondary to immunosuppression. Because symptoms and signs of early infection may be masked by corticosteroids, previous RCTs performed intensive infection surveillance procedures during the study to reduce the risk of superinfection [6,7]. However, these intensive surveillance procedures are not always performed outside of clinical studies. Our analysis showed that the infection risks reported in RCTs and cohort studies were conflicting (Figure 3). It is not known whether restrictive patient selection and infection surveillance procedures in RCTs played a role in making such a difference. Similar to the concern for mortality outcomes, the infection risk of corticosteroid therapy should be evaluated in an adequate time frame because the immunosuppressive effect may develop late in the clinical course. However, most studies evaluated infectious complications in a short duration

Table 3 Subgroup analysis by timing of starting corticosteroid therapy

\begin{tabular}{|c|c|c|c|c|}
\hline Timing of starting steroids & Number of studies & Number of patients & Relative risk (95\% Cl) & $I^{2}$ \\
\hline \multicolumn{5}{|l|}{ Preventive therapy } \\
\hline Randomized controlled trials & 3 & 154 & 1.24 (0.57 to 2.72$)$ & $80 \%$ \\
\hline \multicolumn{5}{|l|}{ Early ARDS ( $\leq 3$ days) } \\
\hline Randomized controlled trials & 3 & 367 & 0.86 (0.71 to 1.04$)$ & $17 \%$ \\
\hline Cohort studies & 4 & 303 & $1.00(0.24$ to 4.20$)$ & $70 \%$ \\
\hline \multicolumn{5}{|l|}{ Persistent ARDS ( $\geq 5$ days) } \\
\hline Randomized controlled trials & 2 & 204 & 0.52 (0.11 to 2.52 ) & $79 \%$ \\
\hline Cohort studies & 3 & 105 & 0.73 (0.44 to 1.23$)$ & $0 \%$ \\
\hline
\end{tabular}

Three studies were excluded in this analysis due to no report of treatment timing. 
Table 4 Comparisons of published meta-analyses

\begin{tabular}{|c|c|c|c|}
\hline Study (Ref.) & Included studies & Summary of study conclusion & Additional remarks \\
\hline $\begin{array}{l}\text { Adhikari et al. } \\
\text { (2004) [9] }\end{array}$ & Three RCTs & $\begin{array}{l}\text { Early high-dose corticosteroids had no effect } \\
\text { on early mortality. Corticosteroids given for } \\
\text { late phase ARDS reduced hospital mortality. }\end{array}$ & $\begin{array}{l}\text { Study interest not focused on corticosteroids; } \\
\text { few studies and small sample size. }\end{array}$ \\
\hline $\begin{array}{l}\text { Agarwal et al. } \\
(2007)[10]\end{array}$ & $\begin{array}{l}\text { Four RCTs and two } \\
\text { cohort studies }\end{array}$ & $\begin{array}{l}\text { Current evidence does not support a role for } \\
\text { corticosteroids in the management of ARDS in } \\
\text { either the early or late stages of the disease. }\end{array}$ & $\begin{array}{l}\text { Excluding the RCTs of preventive use of } \\
\text { corticosteroids; including high-dose } \\
\text { corticosteroid study. }\end{array}$ \\
\hline $\begin{array}{l}\text { Peter et al. } \\
(2008)[11]\end{array}$ & $\begin{array}{l}\text { Nine RCTs (eight RCTs for } \\
\text { mortality analysis) }\end{array}$ & $\begin{array}{l}\text { A definitive role of corticosteroids in the } \\
\text { treatment of ARDS in adults is not established. }\end{array}$ & $\begin{array}{l}\text { Including the RCTs of preventive use of } \\
\text { corticosteroids; excluding pneumonia } \\
\text { studies; using Bayesian random effects } \\
\text { models for data pooling. }\end{array}$ \\
\hline $\begin{array}{l}\text { Tang et al. } \\
\text { (2009) [12] }\end{array}$ & $\begin{array}{l}\text { Four RCTs (three ARDS studies } \\
\text { and one pneumonia study) and } \\
\text { five cohort studies }\end{array}$ & $\begin{array}{l}\text { The use of low-dose corticosteroids was } \\
\text { associated with improved mortality and morbidity } \\
\text { outcomes without increased adverse reactions. }\end{array}$ & $\begin{array}{l}\text { Including a RCT of pneumonia; excluding } \\
\text { studies of high-dose and preventive use } \\
\text { of corticosteroids. }\end{array}$ \\
\hline $\begin{array}{l}\text { Lamontagne } \\
\text { et al. (2010) [13] }\end{array}$ & $\begin{array}{l}\text { Twelve RCTs (six ARDS studies } \\
\text { and six pneumonia studies) }\end{array}$ & $\begin{array}{l}\text { Corticosteroids administered within } 14 \text { days of } \\
\text { disease onset may reduce all-cause mortality. }\end{array}$ & Including six studies of pneumonia. \\
\hline
\end{tabular}

ARDS, acute respiratory distress syndrome; RCTs, randomized controlled trials.

(Additional file 1: e-Table S6) and the infection risk of corticosteroid therapy might, therefore, be underestimated.

External validity should be noted for this meta-analysis. Included individual RCTs reported numerous exclusion criteria for patient enrollment. The results of this metaanalysis should not be generalized to patients with particular comorbidities. Most RCTs excluded patients with underlying diseases that might benefit from corticosteroids, such as inflammatory airway diseases or vasculitis. Were these patients enrolled, the study outcome might be more likely to favor the corticosteroid group. On the other hand, clinical trials also excluded patients with conditions that militate against the use of corticosteroids, such as active gastrointestinal bleeding, disseminated infections, extensive burns or immunocompromised status. Outside the scope of the generalizability of current data, the use of corticosteroids in ARDS should be individually evaluated. Underlying diseases are important considerations to justify the use of corticosteroids.

\section{Strengths and limitations}

The strengths of our study include a comprehensive search strategy to include all studies analyzed in previous meta-analyses but not be restricted to these studies and to evaluate short-term and longer-term outcomes of corticosteroid therapy. The diversity of treatment outcomes among different etiologies of ARDS was also evaluated. These analyses help explore the causes of inconsistency among previous meta-analyses and achieve a more concrete suggestion for the use of corticosteroids in ARDS. With inclusion of the data from cohort studies, the disparity between clinical trials and real-world practice was disclosed, and their consistent results or trends helped to increase the robustness of this meta-analysis. In addition, we performed a sensitivity analysis to test the influence of study pooling strategy, an analysis that previous meta-analyses did not perform. Our study also has limitations. The number of RCTs and sample size were relatively small. There are only two studies in some subgroup analyses and underpower is a concern. Sparse data are another concern for data pooling by the random-effects model. With respect to the evaluation of an etiology-specific response to corticosteroids, the classification of ARDS etiologies was limited because the mix of study populations was diverse among several studies. Finally, study quality might be a confounding factor that we were unable to control in the subgroup analysis when we try to explore the association between follow-up duration and mortality. Earlier studies tend to be of poor quality and their follow-up duration was also shorter.

\section{Conclusions}

ARDS is a heterogeneous disease with various etiologies and clinical courses. The effects of corticosteroids on ARDS were inconsistent in previous studies due to different outcome measures and study populations. This study shows that corticosteroids do not improve longer-term outcomes and may cause harm in certain subgroups of ARDS, such as influenza-related ARDS. Based on current available data, we do not suggest routine use of corticosteroids for ARDS. More clinical trials are needed to improve the overall quality of evidence and to specify the unfavorable and favorable subgroups of ARDS for corticosteroid therapy. Future studies should evaluate short-term as well as longer-term outcomes for comprehensive evaluation of the treatment efficacy of corticosteroids in ARDS.

\section{Key messages}

- ARDS is a heterogeneous disease with various etiologies and clinical courses. The effects of corticosteroids on ARDS were inconsistent in previous studies due to different outcome measures and study populations. 
- This meta-analysis evaluated short-term and longer-term effects of corticosteroids on ARDS mortality. Pooled data showed that corticosteroid therapy did not decrease longer-term mortality.

- The effectiveness of corticosteroid therapy differed in different etiologies of ARDS. Corticosteroids might cause harm in certain subgroups of ARDS patients, such as influenza-related ARDS.

- Current data do not support routine use of corticosteroids for ARDS. More clinical trials are needed to improve the overall quality of evidence and to specify the unfavorable and favorable subgroups of ARDS patients for corticosteroid therapy.

\section{Additional files}

Additional file 1: Contains details of included studies (e-Table S1), quality assessment of included studies (e-Table S2 and e-Table S3), comparability of included cohort studies (e-Table S4), within study comparison of different mortality endpoints (e-Table S5) and definition of infection in included studies (e-Table S6).

Additional file 2: Contains funnel plot for outcome of mortality in randomized controlled trials (e-Figure $\mathrm{S} 1$ ) and cohort studies (e-Figure S2).

\section{Abbreviations}

ARDS: acute respiratory distress syndrome; $\mathrm{Cl}$ : confidence interval: $\mathrm{RCT}$ : randomized clinical trial; RD: risk difference; RR: relative risk.

\section{Competing interests}

The authors declare that they have no competing interests.

\section{Authors' contributions}

SYR and HHL designed the study. SYR, HHL and CTH conducted the analysis and interpretation of the data and drafted the manuscript. PHK, HDW and CJY contributed to the interpretation of the data and critical revision of the manuscript for important intellectual content. All authors read and approved the final manuscript. SYR and HHL are guarantors.

\section{Authors' information}

Sheng-Yuan Ruan, MD; Graduate Institute of Epidemiology and Preventive Medicine, National Taiwan University, Taipei, Taiwan; and Division of Pulmonary and Critical Care Medicine, Department of Internal Medicine, National Taiwan University Hospital, Taipei, Taiwan; Hsien-Ho Lin, MD, ScD; Graduate Institute of Epidemiology and Preventive Medicine, National Taiwan University, Taipei, Taiwan; Chun-Ta Huang, MD, Ping-Hung Kuo, MD, Huey-Dong Wu, MD and Chong-Jen Yu, MD, PhD; Division of Pulmonary and Critical Care Medicine, Department of Internal Medicine, National Taiwan University Hospital, Taipei, Taiwan.

\section{Author details}

${ }^{1}$ Graduate Institute of Epidemiology and Preventive Medicine, National Taiwan University, No.17 Xu-Zhou Road, Taipei 10020, Taiwan. ${ }^{2}$ Division of Pulmonary and Critical Care Medicine, Department of Internal Medicine, National Taiwan University Hospital, Taipei, Taiwan.

Received: 22 January 2014 Accepted: 25 March 2014

Published: 7 April 2014

\section{References}

1. Ranieri VM, Rubenfeld GD, Thompson BT, Ferguson ND, Caldwell E, Fan E, Camporota L, Slutsky AS: Acute respiratory distress syndrome: the Berlin Definition. JAMA 2012, 307:2526-2533.

2. Matthay MA, Ware LB, Zimmerman GA: The acute respiratory distress syndrome. J Clin Invest 2012, 122:2731-2740.
3. Phua J, Badia JR, Adhikari NK, Friedrich JO, Fowler RA, Singh JM, Scales DC, Stather DR, Li A, Jones A, Gattas DJ, Hallett D, Tomlinson G, Stewart TE, Ferguson ND: Has mortality from acute respiratory distress syndrome decreased over time?: a systematic review. Am J Respir Crit Care Med 2009, 179:220-227.

4. Meduri GU, Annane D, Chrousos GP, Marik PE, Sinclair SE: Activation and regulation of systemic inflammation in ARDS: rationale for prolonged glucocorticoid therapy. Chest 2009, 136:1631-1643.

5. Bernard GR, Luce JM, Sprung CL, Rinaldo JE, Tate RM, Sibbald WJ, Kariman K, Higgins S, Bradley R, Metz CA, Harris TR, Brigham KL: High-dose corticosteroids in patients with the adult respiratory distress syndrome. N Engl J Med 1987, 317:1565-1570.

6. Steinberg KP, Hudson LD, Goodman RB, Hough CL, Lanken PN, Hyzy R, Thompson BT, Ancukiewicz M: Efficacy and safety of corticosteroids for persistent acute respiratory distress syndrome. N Engl J Med 2006, 354:1671-1684.

7. Meduri GU, Golden E, Freire AX, Taylor E, Zaman M, Carson SJ, Gibson M, Umberger R: Methylprednisolone infusion in early severe ARDS: results of a randomized controlled trial. Chest 2007, 131:954-963.

8. Meduri GU, Headley AS, Golden E, Carson SJ, Umberger RA, Kelso T, Tolley EA: Effect of prolonged methylprednisolone therapy in unresolving acute respiratory distress syndrome: a randomized controlled trial. JAMA 1998, 280:159-165.

9. Adhikari N, Burns KE, Meade MO: Pharmacologic therapies for adults with acute lung injury and acute respiratory distress syndrome. Cochrane Database Syst Rev 2004, 4, CD004477.

10. Agarwal R, Nath A, Aggarwal AN, Gupta D: Do glucocorticoids decrease mortality in acute respiratory distress syndrome? A meta-analysis. Respirology 2007, 12:585-590.

11. Peter JV, John P, Graham PL, Moran JL, George IA, Bersten A: Corticosteroids in the prevention and treatment of acute respiratory distress syndrome (ARDS) in adults: meta-analysis. BMJ 2008, 336:1006-1009.

12. Tang BM, Craig JC, Eslick GD, Seppelt I, McLean AS: Use of corticosteroids in acute lung injury and acute respiratory distress syndrome: a systematic review and meta-analysis. Crit Care Med 2009, 37:1594-1603.

13. Lamontagne F, Briel M, Guyatt GH, Cook DJ, Bhatnagar N, Meade M: Corticosteroid therapy for acute lung injury, acute respiratory distress syndrome, and severe pneumonia: a meta-analysis of randomized controlled trials. J Crit Care 2010, 25:420-435.

14. Dos Santos CC: Advances in mechanisms of repair and remodelling in acute lung injury. Intensive Care Med 2008, 34:619-630.

15. Moher D, Liberati A, Tetzlaff J, Altman DG: Preferred reporting items for systematic reviews and meta-analyses: the PRISMA statement. PLoS Med 2009, 6:e1000097.

16. Higgins JP, Altman DG, Gotzsche PC, Juni P, Moher D, Oxman AD, Savovic J, Schulz KF, Weeks L, Sterne JA: The Cochrane Collaboration's tool for assessing risk of bias in randomised trials. BMJ 2011, 343:d5928.

17. Wells GA, Shea B, O'Connell D, Peterson J, Welch V, Losos M, Tugwell P: The Newcastle-Ottawa Scale (NOS) for assessing the quality of nonrandomised studies in meta-analyses. http://www.ohri.ca/programs/dinical_epidemiology/ oxford.asp.

18. Brun-Buisson C, Richard JCM, Mercat A, Thiebaut ACM, Brochard L, REVA-SRLF A/H1N1v 2009 Registry Group: Early corticosteroids in severe influenza A/H1N1 pneumonia and acute respiratory distress syndrome. Am J Respir Crit Care Med 2011, 183:1200-1206.

19. Bone RC, Fisher CJ Jr, Clemmer TP, Slotman GJ, Metz CA: Early methylprednisolone treatment for septic syndrome and the adult respiratory distress syndrome. Chest 1987, 92:1032-1036.

20. Higgins JP, Thompson SG, Deeks JJ, Altman DG: Measuring inconsistency in meta-analyses. BMJ 2003, 327:557-560.

21. Weigelt JA, Norcross JF, Borman KR, Snyder WH 3rd: Early steroid therapy for respiratory failure. Arch Surg 1985, 120:536-540.

22. Luce JM, Montgomery AB, Marks JD, Turner J, Metz CA, Murray JF: Ineffectiveness of high-dose methylprednisolone in preventing parenchymal lung injury and improving mortality in patients with septic shock. Am Rev Respir Dis 1988, 138:62-68.

23. Annane D, Sebille V, Bellissant E, Ger-Inf-05 Study Group: Effect of low doses of corticosteroids in septic shock patients with or without early acute respiratory distress syndrome. Crit Care Med 2006, 34:22-30.

24. Fowler AA, Hamman RF, Zerbe GO, Benson KN, Hyers TM: Adult respiratory distress syndrome. Prognosis after onset. Am Rev Respir Dis 1985, 132:472-478.

25. Headley AS, Tolley E, Meduri GU: Infections and the inflammatory response in acute respiratory distress syndrome. Chest 1997, 111:1306-1321. 
26. Keel JBP, Hauser M, Stocker R, Baumann PC, Speich R: Established acute respiratory distress syndrome: benefit of corticosteroid rescue therapy. Respiration 1998, 65:258-264.

27. Varpula T, Pettila V, Rintala E, Takkunen O, Valtonen V: Late steroid therapy in primary acute lung injury. Intensive Care Med 2000, 26:526-531.

28. Song ZF, Guo XH, Wang SY, Xie W, Yin N, Zhang Y, Shan HM, Li WH: Evaluation of glucocorticoid in treatment for patients with acute respiratory distress syndrome. Chinese Crit Care Med 2003, 15:349-353.

29. Lee HS, Lee JM, Kim MS, Kim HY, Hwangbo B, Zo Jl: Low-dose steroid therapy at an early phase of postoperative acute respiratory distress syndrome. Ann Thorac Surg 2005, 79:405-410.

30. Bajwa EK, Khan UA, Januzzi JL, Gong MN, Thompson BT, Christiani DC: Plasma C-reactive protein levels are associated with improved outcome in ARDS. Chest 2009, 136:471-480.

31. Schellongowski $P$, Ullrich $R$, Hieber $C$, Hetz $H$, Losert $H$, Hermann M, Hermann A, Gattringer KB, Siersch V, Rabitsch W, Fuhrmann V, Bojic A, Robak O, Sperr WR, Laczika K, Locker GJ, Staudinger T: A surge of fluassociated adult respiratory distress syndrome in an Austrian tertiary care hospital during the 2009/2010 Influenza A H1N1v pandemic. Wien Klin Wochenschr 2011, 123:209-214.

32. Linko R, Pettila V, Ruokonen E, Varpula T, Karlsson S, Tenhunen J, Reinikainen M, Saarinen K, Perttila J, Parviainen I, Ala-Kokko T, FINNH1N1-Study Group: Corticosteroid therapy in intensive care unit patients with PCR-confirmed influenza $\mathrm{A}(\mathrm{H} 1 \mathrm{~N} 1)$ infection in Finland. Acta Anaesthesiol Scand 2011, 55:971-979.

33. Sibbald WJ, Anderson RR, Reid B, Holliday RL, Driedger AA: Alveolo-capillary permeability in human septic ARDS. Effect of high-dose corticosteroid therapy. Chest 1981, 79:133-142.

34. Seam N, Meduri GU, Wang HH, Nylen ES, Sun JF, Schultz MJ, Tropea M, Suffredini AF: Effects of methylprednisolone infusion on markers of inflammation, coagulation, and angiogenesis in early acute respiratory distress syndrome. Crit Care Med 2012, 40:495-501.

35. Dixon WG, Abrahamowicz M, Beauchamp ME, Ray DW, Bernatsky S, Suissa S, Sylvestre MP: Immediate and delayed impact of oral glucocorticoid therapy on risk of serious infection in older patients with rheumatoid arthritis: a nested case-control analysis. Ann Rheum Dis 2012, 71:1128-1133.

36. Poetker DM, Reh DD: A comprehensive review of the adverse effects of systemic corticosteroids. Otolaryngol Clin North Am 2010, 43:753-768.

37. Gattinoni L, Pelosi P, Suter PM, Pedoto A, Vercesi P, Lissoni A: Acute respiratory distress syndrome caused by pulmonary and extrapulmonary disease. Different syndromes? Am J Respir Crit Care Med 1998, 158:3-11.

38. Santos FB, Nagato LK, Boechem NM, Negri EM, Guimaraes A, Capelozzi VL, Faffe DS, Zin WA, Rocco PR: Time course of lung parenchyma remodeling in pulmonary and extrapulmonary acute lung injury. J Appl Physio/ 2006, 100:98-106.

39. Lee N, Chan PK, Hui DS, Rainer TH, Wong E, Choi KW, Lui GC, Wong BC, Wong RY, Lam WY, Chu IM, Lai RW, Cockram CS, Sung JJ: Viral loads and duration of viral shedding in adult patients hospitalized with influenza. $J$ Infect Dis 2009, 200:492-500.

40. Kim SH, Hong SB, Yun SC, Choi WI, Ahn JJ, Lee YJ, Lee HB, Lim CM, Koh Y: Corticosteroid treatment in critically ill patients with pandemic influenza A/H1N1 2009 infection: analytic strategy using propensity scores. Am J Respir Crit Care Med 2011, 183:1207-1214.

41. Bautista E, Chotpitayasunondh T, Gao Z, Harper SA, Shaw M, Uyeki TM, Zaki SR, Hayden FG, Hui DS, Kettner JD, Kumar A, Lim M, Shindo N, Penn C, Nicholson KG: Clinical aspects of pandemic 2009 influenza A (H1N1) virus infection. N Engl J Med 2010, 362:1708-1719.

42. Confalonieri M, Urbino R, Potena A, Piattella M, Parigi P, Puccio G, Della Porta R, Giorgio C, Blasi F, Umberger R, Meduri GU: Hydrocortisone infusion for severe community-acquired pneumonia: a preliminary randomized study. Am J Respir Crit Care Med 2005, 171:242-248.

43. Casserly B, Gerlach H, Phillips GS, Lemeshow S, Marshall JC, Osborn TM, Levy MM: Low-dose steroids in adult septic shock: results of the Surviving Sepsis Campaign. Intensive Care Med 2012, 38:1946-1954

44. Buttgereit F, Burmester GR, Lipworth BJ: Optimised glucocorticoid therapy: the sharpening of an old spear. Lancet 2005, 365:801-803.

\section{doi:10.1186/cc13819}

Cite this article as: Ruan et al:: Exploring the heterogeneity of effects of corticosteroids on acute respiratory distress syndrome: a systematic review and meta-analysis. Critical Care 2014 18:R63.

\section{Submit your next manuscript to BioMed Central and take full advantage of:}

- Convenient online submission

- Thorough peer review

- No space constraints or color figure charges

- Immediate publication on acceptance

- Inclusion in PubMed, CAS, Scopus and Google Scholar

- Research which is freely available for redistribution 